\title{
Course of activities of daily living in nursing home residents with dementia from admission to 36-month follow-up
}

Reidun Haarr Johansen ${ }^{1 *}\left(\mathbb{D}\right.$, Karoline Olsen ${ }^{1 \dagger}$, Sverre Bergh ${ }^{2,3,4}$, Jūrate Šaltyte Benth ${ }^{5,6,7}$, Geir Selbæk ${ }^{2,8,9}$ and Anne-Sofie Helvik ${ }^{2,10}$

\begin{abstract}
Background: Dementia is affecting both the person with the disease and the family members. It is associated with nursing home admission, and a reduced ability to perform personal activities of daily living (P-ADL). The aim of this study was to examine the association between the severity of dementia and P-ADL function, and to study if additional factors such as neuropsychiatric symptoms, type of nursing home unit, and use of medication were associated with P-ADL function.
\end{abstract}

Methods: A total of 582 nursing home residents with dementia, included at admission to the nursing home, were followed with biannual assessments for 36 months. P-ADL was assessed using the Physical Self-Maintenance scale, and severity of dementia was measured with the Clinical Dementia Rating scale. In addition, neuropsychiatric symptoms, general physical health, and use of medications were assessed at the same time points. Demographic information was collected at baseline. Linear mixed models were estimated.

Results: There was a significant $(p<0.05)$ non-linear decline in P-ADL function over time in analysis not adjusting for any characteristics. More severe dementia at baseline and at the follow-up assessments was associated with lower P-ADL function $(p<0.001)$, with the association being stable over time. A higher level of neuropsychiatric symptoms, not using anti-dementia medication, being in a regular care unit as compared to a special care unit and having poor/ fair general physical health as compared to good/excellent, were associated with a lower P-ADL function.

Conclusion: The association between more severe dementia and lower P-ADL function was stable over a 36-month follow-up period of nursing home residents with dementia. Health care planners and clinicians should be aware of this when planning for and treating nursing home residents.

Keywords: Cognitive impairment, Functional impairment, Behavioural symptoms, Elderly, Home for the aged, Long term care, Functional decline, Psychotropic medication, PSMS, CDR

\footnotetext{
* Correspondence: reidun.haarr@hotmail.com

${ }^{+}$Reidun Haarr Johansen and Karoline Olsen contributed equally to this work. 'Department of Public Health and Nursing, Faculty of Medicine and Health Sciences, Norwegian University of Science and Technology (NTNU), Trondheim, Norway

Full list of author information is available at the end of the article
}

(c) The Author(s). 2020 Open Access This article is licensed under a Creative Commons Attribution 4.0 International License, which permits use, sharing, adaptation, distribution and reproduction in any medium or format, as long as you give appropriate credit to the original author(s) and the source, provide a link to the Creative Commons licence, and indicate if changes were made. The images or other third party material in this article are included in the article's Creative Commons licence, unless indicated otherwise in a credit line to the material. If material is not included in the article's Creative Commons licence and your intended use is not permitted by statutory regulation or exceeds the permitted use, you will need to obtain permission directly from the copyright holder. To view a copy of this licence, visit http://creativecommons.org/licenses/by/4.0/. The Creative Commons Public Domain Dedication waiver (http://creativecommons.org/publicdomain/zero/1.0/) applies to the data made available in this article, unless otherwise stated in a credit line to the data. 


\section{Background}

Newly published data from the United Nations (UN), state that the number of people aged 65 years or older in Europe, has increased from 8\% in 1950 to $19 \%$ in 2019, and it is expected that the proportion of the elderly in the society will continue to increase [1]. The elderly population often has more comorbidities and polypharmacy $[2,3]$, leading to more frailty, and thus, the growing proportion of the elderly population in the society may impose a great burden to the next of kin and the health care system.

In Norway, unlike many other countries, the health care services are public $[4,5]$. The primary health care service is, by law, managed by the local municipalities [6]. Services provided include social services (such as housing and home services), domiciliary care, and institutional care, mainly in nursing homes $(\mathrm{NH})$. In many countries, including Norway, the NHs are institutions that provide fulltime nursing care for people when informal care and/or domiciliary care are not sufficient to fulfil the needs of care, due to the severity of illness and/or disability. Functional impairment, age, dementia, and psychosis are the main reasons for $\mathrm{NH}$ admission [7], with dementia being one of the factors strongest associated with admission to $\mathrm{NH}$ [8-10]. Approximately $80 \%$ of the long-term care residents in Norwegian NHs have dementia according to previous studies [11-13].

Dementia is a syndrome caused by a variety of brain disorders, usually of a chronic progressive nature. A progressive decline in cognitive function is one of the main characteristics of dementia. The primary risk factor for developing dementia is age, and therefore, the rising life expectancies in the society will increase the number of people who develop dementia [14]. The leading type of dementia is Alzheimer's disease (66\%) [14]. Other common causes of dementia are vascular dementia, Lewy body dementia/Parkinson disease with dementia and frontotemporal dementia [15]. According to the ICD-10 criteria for dementia, there must be a decline in memory and other cognitive abilities, such as judgement and thinking, and a decline in emotional control or motivation, without the consciousness being affected [16]. People with dementia utilize health care services more frequently [17], and dementia is not just affecting the person with the disease, but also the family members and the professional health care staff supporting the person with dementia and/or family [18-20]. Individuals with dementia often have neuropsychiatric symptoms (NPS) [21-24]. NPS include psychiatric and behavioural symptoms such as agitation, depression, hallucinations, aggression and apathy. In a descriptive study from 2018, which included the same participants as the present study, $62 \%$ of the residents with dementia had at least one clinically significant NPS at inclusion to the NH
[25]. Dementia is also often associated with a reduced ability to perform activities of daily living [11, 26-31]. Several studies have found a correlation between the brain atrophy in individuals with dementia and their dysfunction in activities of daily living $[32,33]$. The association between dementia and activities of daily living is demonstrated in the ICD-10 criteria for dementia, with one of the criteria being that there is a decline in cognitive abilities which causes impaired performance in everyday activities [16].

Activities of daily living (ADL) describes the ability to perform practical everyday tasks necessary for basic, and more complex self-care. It consists of instrumental ADL (I-ADL), with complex, higher order skills, and personal ADL (P-ADL), with self-maintenance skills, such as dressing, eating, bathing and toileting. A decline in PADL causes individuals to become more dependent of the caregivers and professional support [17, 34, 35].

The association between dementia and declined PADL function has been assessed in several studies and settings [11, 26-28, 31, 36-39], and some of the studies have explored the association in NH settings [11, 26, 28, 36-38]. However, most of these studies used data from various constellations of ADL-items from the mandated Minimum data set (MDS) assessment instrument used in NHs in the USA [26, 36-38]. Very few studies have used internationally accepted and validated P-ADL instruments, using a sum score of predefined aspects of $\mathrm{P}$ ADL $[11,28]$. Furthermore, most of the previous studies, have not adjusted for additional factors potentially important for P-ADL [11, 26, 36-38]. These factors include for example NPS, physical comorbidity, age and medication [28, 40-42].

To our knowledge, there are only two studies that have described the course of P-ADL, adjusted for variables known to have an influence on P-ADL function $[28,31]$. One of the studies included older people receiving domiciliary care [31], and the other included $\mathrm{NH}$ residents only [28]. These studies had follow-up assessments after 18 and 12 months, respectively. More frequent assessments would give a more detailed understanding of the association between dementia and P-ADL function. Furthermore, in the study of $\mathrm{NH}$ residents, the residents were not included consecutively after admission to the $\mathrm{NH}$ [28]. To increase the understanding of the association between dementia and P-ADL function, we wanted to include the participants at the time of admission to the $\mathrm{NH}$. We believed that this would give us the opportunity to explore a possible decline in P-ADL as a consequence of the $\mathrm{NH}$ admission, in other words, to assess whether the time after the admission had an impact on the decline in P-ADL.

The aim of this study was to examine if and how PADL assessed biannually over 36 months changed over 
time in $\mathrm{NH}$ residents. The primary aim was to explore the association between the severity of dementia and PADL function over time in $\mathrm{NH}$ residents. The secondary aim was to assess if and how additional factors such as neuropsychiatric symptoms, type of $\mathrm{NH}$ unit and use of medication were associated with the outcome.

\section{Methods}

\section{Design}

The data was collected from the REDIC-NH study, an observational longitudinal study including participants from a convenience sample of $47 \mathrm{NHs}$ in four Norwegian counties, from both small and large $\mathrm{NHs}$, located in urban and rural areas [43]. The baseline data was collected between March 2012 and November 2014, and the residents were included within one month after admission to the $\mathrm{NH}$. The follow-up data was collected every six months or until the resident left the study, mainly due to death of the resident. The present study includes information from baseline $\left(\mathrm{T}_{1}\right)$ until the 36month follow-up $\left(\mathrm{T}_{7}\right)$.

\section{Setting and participants}

In total, 696 residents with an expected stay longer than four weeks were recruited at admission to the $\mathrm{NH}$. Out of these, 583 had dementia [43]. All residents of 65 years and older were included, as well as residents younger than 65 years with established dementia. The only exclusion criterion was a life expectancy of less than six weeks [43]. In the present study, only those with dementia at admission, and at least one P-ADL assessment were included, resulting in 582 participants in the present study. Dementia was diagnosed at baseline according to the ICD-10 criteria independently by two physicians (SB and GS), with the possibility to consult a third physician [43]. The diagnosis was set as a research diagnosis based on all available collected data but not a clinical work-up of the patient.

\section{Measures}

The outcome variable, personal activities of daily living (PADL), was assessed with the Physical Self-Maintenance Scale (PSMS) [44] in a translated Norwegian version. The scale has been frequently used in Scandinavian studies [11, $13,28,31$ ], and includes six items (toileting, feeding, dressing, grooming, physical ambulation, bathing), each with five response alternatives, with a total score ranging from 6 to 30. Higher scores indicate a lower level of function.

Severity of dementia was measured with the Clinical Dementia Rating (CDR) scale. The scale covers six domains (orientation, memory, problem solving and judgment, personal care, community affairs, and home and hobbies), each with five response alternatives $(0,0.5,1$, $2,3)[45,46]$. The CDR can be scored either according to an algorithm that gives a total score ranging from 0 (no dementia) to 3 (severe dementia) [45], or by a sum score of the six domains (CDR Sum of Boxes, CDR$\mathrm{SoB})$, ranging from 0 to 18 [47]. A higher score indicates more severe dementia. The correlation between the CDR and the CDR-SoB is high $[47,48]$, with the Spearman correlation of 0.87 at baseline in the original study sample [43]. Due to the increased range of values, the CDR-SoB gives important advantages over the CDR when analyzing the data [47], and in the present study the CDR-SoB was used.

Neuropsychiatric symptoms (NPS) were measured using a translated and validated Norwegian version of the Neuropsychiatric Inventory 12-item Nursing Home version (NPI$\mathrm{NH}$ ), including the following symptoms: delusion, hallucination, agitation/aggression, depression/dysphoria, anxiety, euphoria, apathy/indifference, disinhibition, irritability/lability, aberrant motor behavior, night-time behavior disturbances, and appetite and eating disorders [49, 50]. To obtain the item score, the severity of the symptoms (1-3) was multiplied by frequency (1-4), which provides a score from 0 to 12 on each symptom, where a higher sum indicates more severe symptoms. NPI-NH sub-syndrome scores were calculated, based on previous studies in $\mathrm{NH}$ residents $[24,51,52]$. The three sub-syndromes were: affective (including sum of depression and anxiety), psychosis (including sum of delusions and hallucination) and agitation (including sum of agitation/aggression, disinhibition and irritability) [24, 51, 52].

General physical health was assessed using the General Medical Health Rating (GMHR) scale, a one-item global rating scale with four response categories: poor, fair, good and excellent [53]. The scale is previously used in studies including older people with and without dementia [53-55] also in Norway [56]. For analysis, the four categories were dichotomized into poor/fair and good/excellent [25].

Use of psychotropic medications was collected from the medical record of each resident, using the Anatomic Therapeutic Chemical (ACT) Classification System. The medications were grouped into the following categories: antipsychotics (N05A except lithium), antidepressants (N06A), anxiolytics (N05B), hypnotics/sedatives (N05C), and anti-dementia medication (N06D) [57].

Demographic information such as gender, age and marital status was collected from the medical records.

\section{Procedure}

The data collection was performed by healthcare workers in the NHs, mainly registered nurses (74\%), under the supervision of 10 research nurses who had completed a five-day training program. The data collectors went through a twoday training program prior to the data collection. The training program included lessons on dementia, old-age psychiatry, geriatric assessment, and routines for data-collection, ethics, and research principles, in addition to practical 
training in assessment of participants. The data was collected from the medical records of each resident, and from a standardized interview with the residents, the next of kin and the residents' caregivers in the $\mathrm{NH}$.

The residents' capacity to consent to participate in the study was considered by the $\mathrm{NH}$ staff, including the $\mathrm{NH}$ physician. A written consent for the participation was obtained from all residents who had the capacity to give consent. If a resident was lacking the capacity to give consent, their next of kin gave written consent on behalf of the resident, in line with the Norwegian Act on medical and

Table 1 Characteristics of study sample at baseline

\begin{tabular}{|c|c|c|c|}
\hline Characteristics & & & $\mathrm{N}$ \\
\hline Age (years) & Mean (SD) & $84.1(7.5)$ & 579 \\
\hline Women & N (\%) & $374(64.3)$ & 582 \\
\hline Single as marital status & N (\%) & $389(67.7)$ & 582 \\
\hline \multicolumn{4}{|l|}{ GMHR } \\
\hline Poor & N (\%) & $60(10.8)$ & 557 \\
\hline Fair & N (\%) & $220(39.5)$ & 557 \\
\hline Good & N (\%) & $250(44.9)$ & 557 \\
\hline Excellent & N (\%) & $27(4.8)$ & 557 \\
\hline CDR-SoB & Mean (SD) & $11.2(3.6)$ & 575 \\
\hline \multicolumn{4}{|l|}{ Type of dementia } \\
\hline$A D$ & N (\%) & $414(71.0)$ & 582 \\
\hline VAD & N (\%) & $46(7.9)$ & 582 \\
\hline FTD & N (\%) & $47(8.1)$ & 582 \\
\hline LBD/PD & N (\%) & $22(3.8)$ & 582 \\
\hline ADNAD & N (\%) & $11(1.9)$ & 582 \\
\hline Unspecified & N (\%) & $42(7.2)$ & 582 \\
\hline \multicolumn{4}{|l|}{ NPI-NH } \\
\hline Agitation sub-syndrome & Mean (SD) & $4.5(7.3)$ & 56 \\
\hline Psychosis sub-syndrome & Mean (SD) & $1.9(4.2)$ & 560 \\
\hline Affective disorders sub-syndrome & Mean (SD) & $3.9(5.9)$ & 572 \\
\hline Apathy & Mean (SD) & $1.3(2.7)$ & 570 \\
\hline \multicolumn{4}{|l|}{ Use of psychotropic medication } \\
\hline Antipsychotics & N (\%) & $71(12.2)$ & 582 \\
\hline Antidepressants & N (\%) & $167(28.7)$ & 582 \\
\hline Anxiolytics & N (\%) & $89(15.3)$ & 582 \\
\hline Hypnotics/Sedatives & $N(\%)$ & $128(22.0)$ & 582 \\
\hline Anti-dementia medication & N (\%) & $163(28.0)$ & 582 \\
\hline \multicolumn{4}{|l|}{ NH characteristics } \\
\hline $\mathrm{RU}$ & N (\%) & $367(63.1)$ & 82 \\
\hline SCU & N (\%) & $215(36.9)$ & 582 \\
\hline
\end{tabular}

GMHR General Medical Health rating scale, $C D R-S o B$ The sum score of the domains in the Clinical Dementia Rating scale, $A D$ Alzheimer's disease, VAD Vascular dementia, FTD Frontotemporal dementia, $L B D / P D$ Lewy body dementia/Parkinson's disease, ADNAD Alzheimer's disease mixed type, NPI-NH Neuropsychiatric Inventory 12-item Nursing Home version, $\mathrm{NH}$ Nursing home, $R U$ Regular unit, SCU Special care unit health research [58]. The Regional Ethics Committee for Medical Research (REC) in South Eastern-Norway has approved the study (2011/1738a) [43].

\section{Data analysis}

Sample characteristics at baseline were presented as means and standard deviations (SD) or frequencies and percentages.

A linear mixed model with fixed effects for nonlinear (third order) time component was estimated first to assess time trend in P-ADL-scores. Next, two models were estimated with CDR-SoB as additional fixed effect along with interaction terms between CDR-SoB and time. Model 1 included CDR-SoB assessed at baseline, while CDR-SoB measured simultaneously with P-ADL was included into Model 2. A significant interaction between CDR-SoB and time would imply a varying association between CDR-SoB and P-ADL throughout the follow-up period. Finally, Model 1 was adjusted for predefined clinical and demographic characteristics all measured at baseline, while Model 2 was adjusted for characteristics measured longitudinally whenever possible. All models included random effects for residents nested within NHs. Even though the linear mixed model allows inclusion of all available observations, also from dropouts, the dropouts may introduce bias. Therefore, baseline characteristics of dropouts and those staying in the study were compared.

All analyses were performed in SPSS version 25 and SAS version 9.4. Results with $P$-values below 0.05 were considered statistically significant. All tests were two-sided.

\section{Results}

\section{Sample characteristics}

The total number of participants assessed at baseline for P-ADL was 582. The mean (SD) age of these participants was 84.1 (7.5) years, ranging from 49 to 105 years. In total, $374(64.3 \%)$ of the participants were women

Table 2 Number of participants at each assessment in the study sample

\begin{tabular}{llllllll}
\hline & $\mathbf{T}_{\mathbf{1}}$ & $\mathbf{T}_{\mathbf{2}}$ & $\mathbf{T}_{\mathbf{3}}$ & $\mathbf{T}_{\mathbf{4}}$ & $\mathbf{T}_{\mathbf{5}}$ & $\mathbf{T}_{\mathbf{6}}$ & $\mathbf{T}_{\mathbf{7}}$ \\
\hline Number included & 582 & 469 & 387 & 322 & 269 & 222 & 171 \\
Number assessed & 582 & 436 & 372 & 305 & 260 & 207 & 166 \\
Number left & & 114 & 82 & 65 & 53 & 47 & 51 \\
$\quad$ & 84 & 67 & 61 & 51 & 42 & 49 \\
$\quad$ Due to death & 30 & 15 & 4 & 2 & 5 & 2 \\
$\quad$ Other reasons & 1 & & 2 & & & 1 \\
$\quad$ NH withdrawn & 4 & 2 & & & & \\
$\quad$ Resident withdrawn & 13 & 5 & 2 & 1 & 5 & 1 \\
$\quad$ Moved to another unit of NH & 12 & 8 & & 1 & & \\
$\quad$ Moved home & & & & & &
\end{tabular}

$T_{1}$ : baseline, $T_{2}$ : 6-month assessment, $T_{3}$ : 12-month assessment, $T_{4}$ : 18-month assessment, $\mathrm{T}_{5}$ : 24-month assessment, $\mathrm{T}_{6}$ : 30-month assessment, $\mathrm{T}_{7}$ : 36-month assessment, $\mathrm{NH}$ : nursing home 
Table 3 P-ADL score at seven time points

\begin{tabular}{llll}
\hline Time point & Min & Max & Mean (SD) \\
\hline $\mathrm{T}_{1}$ & 6 & 27 & $15.3(4.5)$ \\
$\mathrm{T}_{2}$ & 6 & 27 & $15.9(4.8)$ \\
$\mathrm{T}_{3}$ & 7 & 30 & $16.8(4.7)$ \\
$\mathrm{T}_{4}$ & 8 & 30 & $17.7(4.8)$ \\
$\mathrm{T}_{5}$ & 8 & 29 & $18.7(4.8)$ \\
$\mathrm{T}_{6}$ & 7 & 29 & $19.7(4.6)$ \\
$\mathrm{T}_{7}$ & 8 & 30 & $20.3(4.8)$ \\
\hline
\end{tabular}

Higher P-ADL score indicates lower function

$\mathrm{T}_{1}$ : baseline, $\mathrm{T}_{2}$ : 6-month assessment, $\mathrm{T}_{3}$ : 12-month assessment, $\mathrm{T}_{4}$ : 18-month assessment, $T_{5}$ : 24-month assessment, $T_{6}$ : 30-month assessment, $T_{7}$ :

36-month assessment

(Table 1). The mean baseline CDR-SoB score was 11.2 (3.6). The mean length of stay was 662 days (SD 383 days). At 36 months, 166 participants were assessed (Table 2). The main reason for leaving the study was death $(N=354)$. Those leaving the study were older $(p=$ $0.001)$, had higher PSMS score $(p<0.001)$, higher NPIaffective sub-syndrome score $(p=0.017)$, were more often males $(p=0.026)$, and hade more often poor/fair GMHR $(\mathrm{p}<0.001)$.

\section{Factors associated with P-ADL}

The mean P-ADL score at baseline and at the biannual follow-up time points is presented in Table 3. At baseline the mean P-ADL score was 15.3 (4.5) and at the 36month follow-up the score was 20.3 (4.8). There was a significant non-linear decline in P-ADL function over time in unadjusted linear mixed model (Fig. 1).
In both unadjusted and adjusted Model 1 (Table 4), higher baseline CDR-SoB was associated with lower PADL function (higher PSMS-score). This association was stable throughout the follow-up period (non-significant interaction terms), as illustrated in Fig. 2. Furthermore, in adjusted Model 1, not being single $(p=0.016)$, having poor/fair as compared to good/excellent GMHR $(p<$ $0.001)$ and more apathy $(p=0.029)$ at baseline were associated with lower P-ADL function at each assessment.

In unadjusted and adjusted Model 2 (Table 5), higher CDR-SoB measured simultaneously with P-ADL was associated with lower P-ADL function, with the association being stable over time (Fig. 3). In adjusted Model 2 , having poor/fair as compared to good/excellent GMHR $(p<0.001)$, more apathy $(\mathrm{p}<0.001)$, agitation sub-syndrome $(p=0.002)$, affective sub-syndrome $(p=$ 0.001), not using anti-dementia medication ( $\mathrm{p}<0.001)$, and being a Regular unit (RU) resident compared to a Special care unit $(\mathrm{SCU})$ resident $(p=0.009)$, all assessed simultaneously with P-ADL, were significantly associated with a lower P-ADL function.

\section{Discussion}

This study of $582 \mathrm{NH}$ residents with established dementia, followed with biannual assessments from admission to 36 months, showed that the degree of dementia (assessed with the CDR-SoB) at baseline, and the course of dementia at the follow-up assessments, were associated with the degree of P-ADL function. More severe dementia both at baseline and at the follow-up assessments was associated

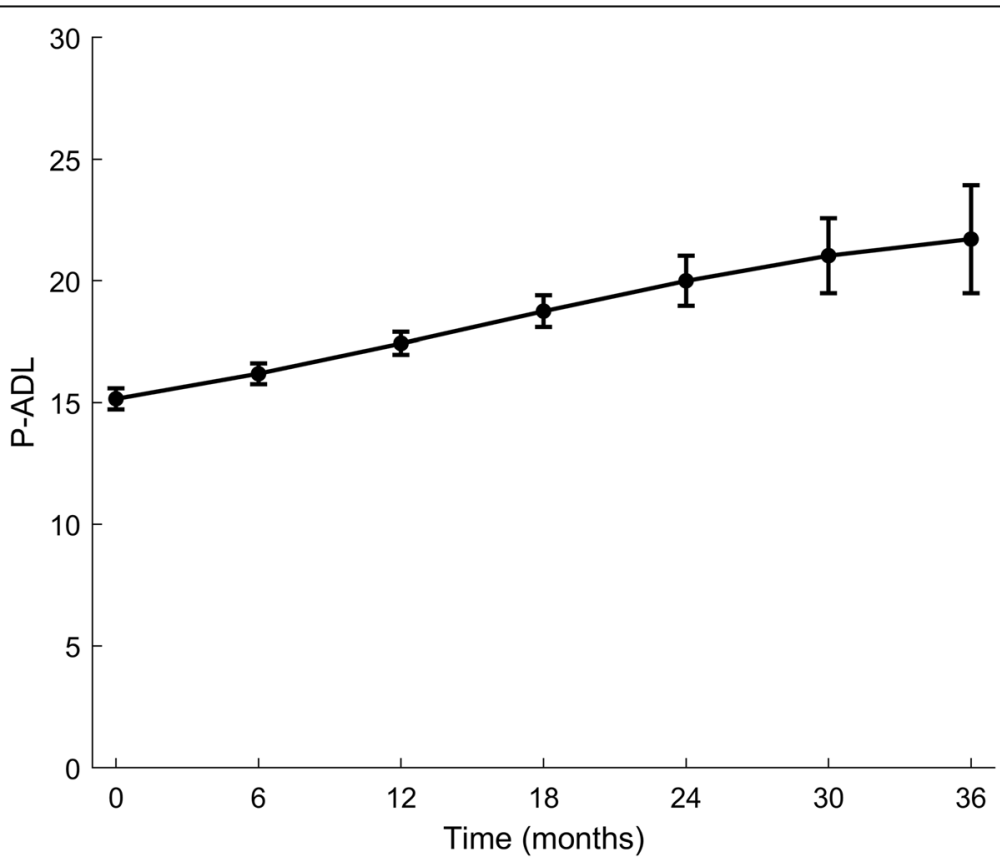

Fig. 1 Time trend (unadjusted) in P-ADL. P-ADL: Personal Activities of Daily Living 
Table 4 Model 1: Results of linear mixed model for effect of dementia (CDR-SoB) measured at baseline on P-ADL level over time

\begin{tabular}{|c|c|c|c|c|}
\hline \multirow[t]{2}{*}{ Covariates } & \multicolumn{2}{|c|}{ Unadjusted models } & \multicolumn{2}{|l|}{ Adjusted models } \\
\hline & Regr. coeff. (SE) & p-value ${ }^{1}$ & Regr. coeff. (SE) & p-value ${ }^{1}$ \\
\hline \multicolumn{5}{|l|}{ Effect of main variable } \\
\hline Time & $0.19(0.12)$ & 0.109 & $0.19(0.12)$ & 0.102 \\
\hline Time*Time & $0.01(0.01)$ & 0.198 & $0.01(0.01)$ & 0.207 \\
\hline Time*Time*Time & $-0.0003(0.0002)$ & 0.053 & $-0.0003(0.0002)$ & 0.054 \\
\hline CDR-SoB BL & $0.59(0.05)$ & $<0.001$ & $0.57(0.06)$ & $<0.001$ \\
\hline Time*CDR-SoB BL & $-0.004(0.01)$ & 0.726 & $-0.003(0.01)$ & 0.736 \\
\hline Time* Time ${ }^{*}$ CDR-SoB BL & $-0.0006(0.0008)$ & 0.438 & $-0.0006(0.0008)$ & 0.440 \\
\hline Time*Time*Time* CDR-SoB BL & $0.00002(0.00002)$ & 0.176 & $0.00002(0.00002)$ & 0.175 \\
\hline \multicolumn{5}{|c|}{ Effect of additional variables at baseline } \\
\hline \multicolumn{5}{|l|}{ Socio-demographic information } \\
\hline Age (per years) & $0.007(0.02)$ & 0.771 & $0.01(0.02)$ & 0.669 \\
\hline Women & $-0.53(0.34)$ & 0.126 & $-0.14(0.36)$ & 0.702 \\
\hline Single & $-0.81(0.36)$ & 0.023 & $-0.91(0.38)$ & 0.016 \\
\hline \multicolumn{5}{|l|}{ GMHR } \\
\hline Poor / Fair (Good/Excellent- ref.) & $1.89(0.33)$ & $<0.001$ & $1.68(0.33)$ & $<0.001$ \\
\hline \multicolumn{5}{|l|}{ NPI-NH } \\
\hline Agitation sub-syndrome & $0.006(0.02)$ & 0.812 & $0.02(0.03)$ & 0.379 \\
\hline Psychosis sub-syndrome & $-0.02(0.04)$ & 0.579 & $-0.03(0.05)$ & 0.521 \\
\hline Affective sub-syndrome & $-0.02(0.03)$ & 0.577 & $-0.04(0.03)$ & 0.231 \\
\hline Apathy & $0.15(0.06)$ & 0.020 & $0.14(0.06)$ & 0.029 \\
\hline \multicolumn{5}{|l|}{ Use of psychotropic medication } \\
\hline Antipsychotics & $-0.38(0.50)$ & 0.454 & $-0.10(0.51)$ & 0.850 \\
\hline Antidepressants & $0.14(0.36)$ & 0.695 & $0.18(0.37)$ & 0.631 \\
\hline Anxiolytics & $-0.41(0.45)$ & 0.370 & $-0.46(0.46)$ & 0.324 \\
\hline Hypnotics/Sedatives & $0.49(0.39)$ & 0.210 & $0.50(0.39)$ & 0.196 \\
\hline Anti-dementia medication & $-0.98(0.36)$ & 0.007 & $-0.63(0.36)$ & 0.084 \\
\hline \multicolumn{5}{|l|}{ NH Characteristics } \\
\hline $\mathrm{RU}$ (SCU - ref.) & $1.06(0.37)$ & 0.004 & $0.51(0.39)$ & 0.188 \\
\hline
\end{tabular}

CDR-SoB: The sum score of the domains in the Clinical Dementia Rating scale, BL: Baseline, GMHR: General Medical Health rating scale, NPI-NH: Neuropsychiatric Inventory 12-item Nursing Home version, NH: Nursing home, RU: Regular unit, SCU: Special care unit

$N=515$ at $\mathrm{T}_{1}, N=393$ at $\mathrm{T}_{2}, N=332$ at $\mathrm{T}_{3}, N=271$ at $\mathrm{T}_{4}, N=233$ at $\mathrm{T}_{5}, \mathrm{~N}=184$ at $\mathrm{T}_{6}, \mathrm{~N}=147$ at $\mathrm{T}_{7}$

$T_{1}$ : baseline, $T_{2}$ : 6-month assessment, $T_{3}:$ 12-month assessment, $T_{4}$ : 18-month assessment, $T_{5}: 24$-month assessment, $T_{6}$ : 30-month assessment, $T_{7}$ :

36-month assessment

${ }^{1}$ Bold text indicate $p$-value $<0.05$

with lower P-ADL function, with the association being stable over time.

When looking at the P-ADL function adjusted for dementia assessed simultaneously with P-ADL, there was a decline in P-ADL function over time, both in unadjusted and adjusted models. This is in line with previous studies, both among $\mathrm{NH}$ residents and community dwelling elderly with dementia [26, 28, 31, 36-39]. However, none of these studies assessing older adults with dementia in NHs included the residents consecutively after admission to the $\mathrm{NH}$. By including the residents at the time of admission, as was done in the present study, the changes that might occur due to the time spent in the
$\mathrm{NH}$, will be the same for all the participants, and thus the study sample will be more homogenous when assessed over time.

Many studies have shown that more severe dementia is associated with lower P-ADL function in $\mathrm{NH}$ residents $[26,28,36-38]$. In the present study, we also found that the association between P-ADL function and degree of dementia was stable over time. In a 52-month follow-up study of $\mathrm{NH}$ residents from Norway, the rate of decline in P-ADL function explained by the degree of dementia, decreased during follow-up [28], which differs from the present study. The follow-up time in that study was considerably longer than in the present study, and it is not 


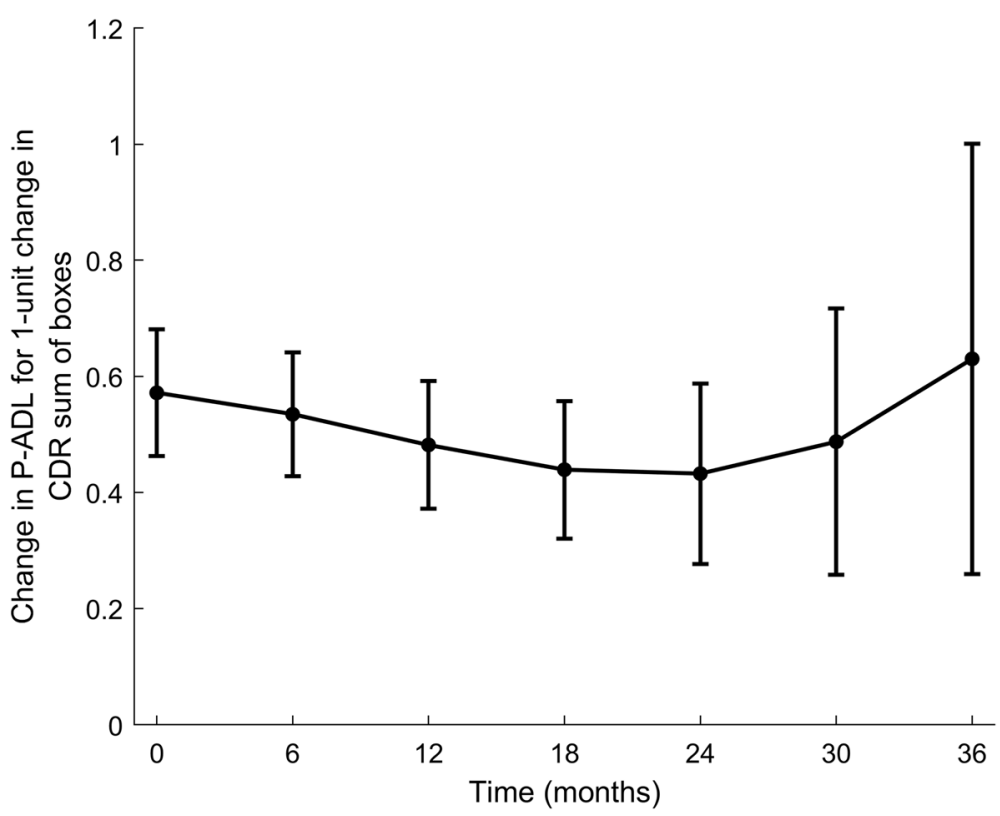

Fig. 2 Association between P-ADL score (PSMS) and cognition (CDR-SoB) at baseline in time adjusted for covariates. PSMS: Physical Self Maintenance Scale, CDR-SoB: The sum score of the domains in the Clinical Dementia Rating scale

clear whether a 52-month follow-up with biannual assessments of the present study would show the same results. Furthermore, the NH study mentioned above had few follow-ups (3 in total), and the $\mathrm{NH}$ residents were not included consecutively after admission to the $\mathrm{NH}$. This may possibly explain the differences in the results between the 52-month study and the present study.

It could be questioned whether the P-ADL of an individual with dementia under 65 years could be compared to the P-ADL of an older person with dementia. Our clinical experience is that those being admitted to a Norwegian nursing home with dementia are in a state that makes municipal domiciliary care insufficient, due to dementia, P-ADL function and/or NPS, independent of age. With the PSMS scale assessing very basic activities of daily living, the measured P-ADL are comparable even if the age range of those admitted to the nursing home are broad. Nevertheless, age adjustments in the analysis should be performed, as was done in this study. However, in the present nursing home study where all participants were included at admission to the nursing home, we did not find an association between age and $\mathrm{P}-\mathrm{ADL}$ or decline in P-ADL. In line with this finding, a Japanese study of persons with dementia living at home found no difference in P-ADL decline in those of 75 years or older compared to younger people [59]. However, a previous Norwegian Nursing home study from 2015 found higher age associated with lower P-ADL function [31].

In several previous studies, both among participants with and without dementia, NPS have been found to be associated with P-ADL function [28, 31, 40, 41, 60-62]. In the present study, we found that more apathy symptoms, and higher agitation and affective sub-syndrome scores were associated with a lower P-ADL function. Even though we found an association between NPSsyndromes and P-ADL function, it remains unclear whether the worsening of NPS gives a lower P-ADL function, or if it is the other way around. However, an explanation for these results, can be that there is a common underlying reason, that gives both more NPS, and a lower P-ADL function. Several structural changes in the brain have been associated with problems in P-ADL function [32, 33, 63]. Changes in some of the same areas have been associated with having NPS [64]. This suggests that there could be common underlying structural changes in the brain that lead to both more NPS and problems in P-ADL function.

In the present study, the use of anti-dementia medication was associated with a better P-ADL function, which is in line with previous studies [28, 31, 34, 65]. This association remained significant even when controlling for additional factors, suggesting that clinicians may consider using these medications with the intention of improving the residents' P-ADL function, and not only their cognitive function. It is well known that there are a variety of structural changes in the brain in the different types of dementia. Studies have shown that anti-dementia medication can delay these structural changes [66]. Many of the same areas are affected in individuals with a low P-ADL function, and our results could thereby be explained by the fact 
Table 5 Model 2: Results of linear mixed model for effect of dementia (CDR-SoB) measured longitudinally on P-ADL level over time

\begin{tabular}{|c|c|c|c|c|}
\hline \multirow[t]{2}{*}{ Covariates } & \multicolumn{2}{|l|}{ Unadjusted models } & \multicolumn{2}{|l|}{ Adjusted models } \\
\hline & Regr. coeff. (SE) & p-value ${ }^{1}$ & Regr. coeff. (SE) & p-value ${ }^{1}$ \\
\hline \multicolumn{5}{|l|}{ Effect of main variable } \\
\hline Time & $0.25(0.12)$ & 0.038 & $0.27(0.12)$ & 0.021 \\
\hline Time*Time & $0.005(0.009)$ & 0.580 & $-0.0004(0.009)$ & 0.964 \\
\hline Time*Time*Time & $-0.0002(0.0002)$ & 0.267 & $-0.00007(0.0002)$ & 0.687 \\
\hline CDR-SoB & $0.61(0.05)$ & $<0.001$ & $0.55(0.05)$ & $<0.001$ \\
\hline Time*CDR-SoB & $-0.01(0.01)$ & 0.242 & $-0.01(0.01)$ & 0.193 \\
\hline Time ${ }^{*}$ Time $^{*}$ CDR-SoB & $0.0001(0.0008)$ & 0.887 & $0.0003(0.0008)$ & 0.672 \\
\hline Time*Time*Time* CDR-SoB & $0.000006(0.00002)$ & 0.704 & $-0.00000001(0.00002)$ & 0.996 \\
\hline \multicolumn{5}{|c|}{ Effect of additional variables at baseline } \\
\hline \multicolumn{5}{|l|}{ Socio-demographic information } \\
\hline Age (per years) & $0.003(0.02)$ & 0.886 & $0.01(0.02)$ & 0.530 \\
\hline Women & $-0.49(0.33)$ & 0.143 & $-0.23(0.32)$ & 0.476 \\
\hline Single & $-0.65(0.30)$ & 0.028 & $-0.46(0.29)$ & 0.116 \\
\hline \multicolumn{5}{|c|}{ Effect of additional variables measured longitudinally } \\
\hline \multicolumn{5}{|l|}{ GMHR } \\
\hline Poor / Fair (Good/Excellent- ref.) & $2.04(0.16)$ & $<0.001$ & $1.77(0.16)$ & $<0.001$ \\
\hline \multicolumn{5}{|l|}{ NPI-NH } \\
\hline Agitation sub-syndrome & $0.07(0.01)$ & $<0.001$ & $0.04(0.01)$ & 0.002 \\
\hline Psychosis sub-syndrome & $0.07(0.02)$ & 0.001 & $-0.002(0.02)$ & 0.915 \\
\hline Affective sub-syndrome & $0.11(0.02)$ & $<0.001$ & $0.06(0.02)$ & 0.001 \\
\hline Apathy & $0.22(0.03)$ & $<0.001$ & $0.14(0.03)$ & $<0.001$ \\
\hline \multicolumn{5}{|l|}{ Use of psychotropic medication } \\
\hline Antipsychotics & $0.19(0.26)$ & 0.450 & $0.08(0.24)$ & 0.730 \\
\hline Antidepressants & $-0.003(0.21)$ & 0.988 & $-0.17(0.20)$ & 0.391 \\
\hline Anxiolytics & $0.06(0.22)$ & 0.780 & $0.03(0.21)$ & 0.894 \\
\hline Hypnotics/Sedatives & $0.42(0.21)$ & 0.041 & $0.17(0.20)$ & 0.382 \\
\hline Anti-dementia medication & $-1.44(0.22)$ & $<0.001$ & $-1.17(0.21)$ & $<0.001$ \\
\hline \multicolumn{5}{|l|}{ NH Characteristics } \\
\hline RU (vs SCU) & $0.71(0.24)$ & 0.003 & $0.59(0.23)$ & 0.009 \\
\hline
\end{tabular}

CDR-SoB: The sum score of the domains in the Clinical Dementia Rating scale, BL: Baseline, GMHR: General Medical Health rating scale, NPI-NH: Neuropsychiatric Inventory 12-item Nursing Home version, $\mathrm{NH}$ : Nursing home, RU: Regular unit, SCU: Special care unit

$\mathrm{N}=515$ at $\mathrm{T}_{1}, N=383$ at $\mathrm{T}_{2}, N=320$ at $\mathrm{T}_{3}, N=241$ at $\mathrm{T}_{4}, N=212$ at $\mathrm{T}_{5}, N=157$ at $\mathrm{T}_{6}, N=121$ at $\mathrm{T}_{7}$

$\mathrm{T}_{1}$ : baseline, $\mathrm{T}_{2}$ : 6-month assessment, $\mathrm{T}_{3}$ : 12-month assessment, $\mathrm{T}_{4}$ : 18-month assessment, $\mathrm{T}_{5}: 24$-month assessment, $\mathrm{T}_{6}$ : 30-month assessment, $\mathrm{T}_{7}$ :

36-month assessment

${ }^{1}$ Bold text indicate $p$-value $<0.05$

that anti-dementia medication also delays the changes in the brain associated with the loss of P-ADL function. To our knowledge, however, this association has not yet been explored, and further research is therefore required to explore the impact anti-dementia medication has on the brain, as well as on P-ADL function. However, another explanation for the results in the present study, can be that the residents with the lowest P-ADL function may not be able to utilize the possibly low effect of the anti-dementia medication. Thus, it may be a lower indication for giving these residents anti-dementia medication, and there will therefore be fewer people with low P-ADL function among the residents who uses these medications.

As expected, there was an association between P-ADL function and GMHR. In addition, it was found that belonging to a SCU at a $\mathrm{NH}$ was associated with better PADL function, compared to those who belonged to a RU. We do not know if the reasons for getting these results are due to differences in the structure and staffing between RU and SCU, or other factors, such as rest confounding. 


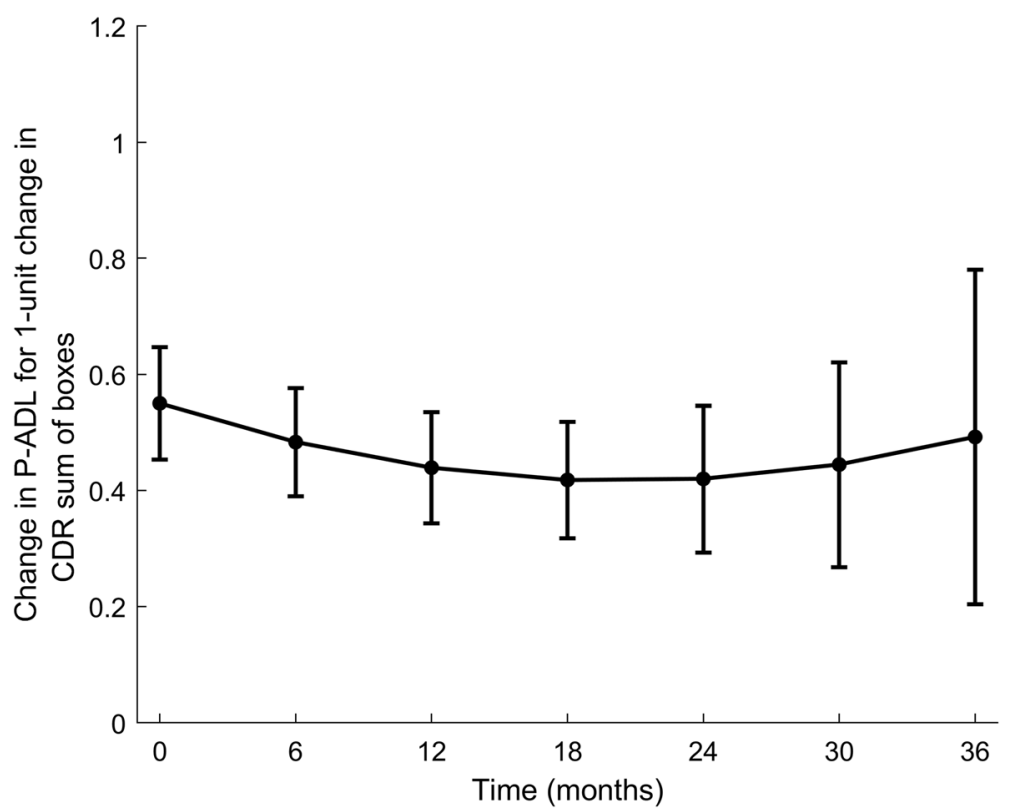

Fig. 3 Association between P-ADL score (PSMS) and cognition (CDR-SoB) in time adjusted for covariates. PSMS: Physical Self Maintenance Scale, CDR-SoB: The sum score of the domains in the Clinical Dementia Rating scale

\section{Strengths and limitations of the study}

One of the main strengths of the present study, is that all the participants were included at the time they were admitted to the $\mathrm{NH}$, and they were followed with biannual assessments for a long follow-up time (36 months). Furthermore, the study used several validated measuring tools, such as PSMS for P-ADL and NPI-NH for NPS. In addition, the results in the present study were adjusted for variables known to have an influence on P-ADL function, in contrast to many previous similar studies [11, 26, 36, 37].

Despite the strengths of the study, there are also limitations. The main weakness in this study is many dropouts, mostly due to death, leading to fewer participants and less data collected. To accommodate any degree of imbalance in the data, a linear mixed model was used. This model is well-suited for analysing data with missing values and dropouts, by including all available data. However, those leaving the study were older and had poorer functioning and physical health than those participating. These findings may imply some degree of bias, but they also indicate that the decline in P-ADL might be underestimated rather than overestimated.

Due to the prospective design of the study, it was necessary to include all $\mathrm{NH}$ residents when they were admitted to a NH. In order to restrict time of inclusion, the study included new residents at several NHs over a large geographical area. We consider this as a strength, because it gives a better representativity than including only a few NHs over a smaller geographical area. On the other hand, it also led to many research coordinators and data collectors involved in the study. This may have caused some differences in interpreting the assessment protocol and tools, which might have reduced the data validity. To secure as high validity of the data as possible, the research coordinators completed a five-day training program, and the data collectors completed a two-day training program, prior to the data collection. Despite this, we cannot rule out the possibility of differences in the data collection.

It is also worth mentioning the proxy reporting of $\mathrm{P}$ $\mathrm{ADL}$ and symptoms as a potential source for bias, however, it is recommended that P-ADL functioning is based in observation by care-taker in individuals with more severe cognitive impairment $[41,67]$.

Even though the study adjusted for many variables relevant for P-ADL function, the analysis did not include information about education. Some previous studies have shown that educational background has an impact on P-ADL function [68-70]. However, to our knowledge, there is only one study that has explored this association among people with dementia [28], and this study did not find education to have a significant impact on P-ADL. Thus, since the importance of education for the association between severity of dementia and P-ADL in $\mathrm{NH}$ residents is still uncertain, we cannot exclude the possibility that information about education could have influenced the estimates in the present study.

\section{Conclusion}

This 36-months longitudinally study of $\mathrm{NH}$ residents with dementia, followed with biannual assessments $(N=$ 
582 at baseline, and $N=166$ at 36 -months), found that more severe dementia at baseline and at the follow-up assessments was associated with lower P-ADL function. This association was stable over time. The health care planners and clinicians should therefore pay attention to degree of dementia, and other factors associated with PADL function in $\mathrm{NH}$ residents, in order to improve the quality of care for the residents with dementia, and to help maintain their level of function as long as possible.

\begin{abstract}
Abbreviations
$\mathrm{NH}$ : Nursing home; RU: Regular unit; SCU: Special care unit; NPS: Neuropsychiatric symptoms; ADL: Activities of daily living; IADL: Instrumental activities of daily living; P-ADL: Personal activities of daily living; PSMS: Physical Self-Maintenance Scale; MDS: Minimum Data Set;

BL: Baseline; T1: baseline; T2: 6-month assessment; T3: 12-month assessment; T4: 18-month assessment; T5: 24-month assessment; T6: 30-month assessment; T7: 36-month assessment; CDR: Clinical Dementia Rating; CDRSoB: The sum score of the domains in the Clinical Dementia Rating scale; NPI-NH: Neuropsychiatric Inventory 12-item Nursing Home version; GMHR: General Medical Health rating scale; ATC: Anatomic Therapeutic Chemical; REC: Regional Ethics Committee for Medical Research; SD: Standard Deviations; AD: Alzheimer's disease; VAD: Vascular dementia; FTD: Frontotemporal dementia; LBD/PD: Lewy body dementia/Parkinson's disease; ADNAD: Alzheimer's disease mixed type
\end{abstract}

\section{Acknowledgements}

We wish to acknowledge Ingrid Bondevik for her help in language editing and proofreading.

\section{Authors' contributions}

$\mathrm{RHJ}$ og KO have contributed equally throughout the process of preparing the manuscript. They conducted the first analysis, interpreted the findings and drafted the manuscript. ASH had the research idea and participated in the primary analysis, interpretation of the results and drafting of the manuscript. SB and GS were responsible for the study design and the data collection. JSB conducted the main statistical analyses. All authors participated in the interpretation of the study results and in editing the manuscript, and they have read and approved the final manuscript.

\section{Funding}

The REDIC-NH study was administrated by the Research Centre for Agerelated Functional decline and Disease, Innlandet Hospital Trust, and was initiated by the Norwegian Health Directorate, which also provided funding for the data collection. In the present study of previous collected data, the analysis and preparation of the manuscript were done without any funding.

\section{Availability of data and materials}

The datasets generated and/or analysed during the current study are available for researchers in cooperation with the data owner, the Research Centre for Age-related Functional decline and Disease, Innlandet Hospital Trust. Information is available on the following page link: https://sykehusetinnlandet.no/avdelinger/alderspsykiatrisk-avdeling/forskningssenteret-foraldersrelatert-funksjonssvikt-og-sykdom.

\section{Ethics approval and consent to participate}

The residents' capacity to consent to participate in the study was considered by the $\mathrm{NH}$ staff, including the $\mathrm{NH}$ physician. A written consent for the participation was obtained from all residents who had the capacity to give consent. If a resident was lacking the capacity to give consent, their next of kin gave written consent on behalf of the resident. The Regional Ethics Committee for Medical Research in South Eastern-Norway (REC) has ap proved the study (2011/1738a).

\section{Consent for publication}

Not applicable.

\section{Competing interests}

The authors declares that they have no competing interests.

\section{Author details}

Department of Public Health and Nursing, Faculty of Medicine and Health Sciences, Norwegian University of Science and Technology (NTNU), Trondheim, Norway. ${ }^{2}$ Norwegian National Advisory Unit on Ageing and Health, Vestfold Hospital Trust, Tønsberg, Norway. ${ }^{3}$ Research Centre for Age-related Functional decline and Disease, Innlandet Hospital Trust, Ottestad, Norway. ${ }^{4}$ Faculty of Medicine, Institute of Health and Society, University of Oslo, Oslo, Norway. Institute of Clinical Medicine, University of Oslo, Oslo, Norway. ${ }^{6}$ Health Services Research Unit, Akershus University Hospital, Lørenskog, Norway. ${ }^{7}$ Centre for Old Age Psychiatric Research, Innlandet Hospital Trust, Ottestad, Norway. ${ }^{8}$ Faculty of Medicine, University of Oslo, Oslo, Norway. ${ }^{9}$ Geriatric Department, Oslo University Hospital, Oslo, Norway. ${ }^{10}$ General Practice Research unit, Department of Public Health and Nursing, Faculty of Medicine and Health Sciences, Norwegian University of Science and Technology (NTNU), Trondheim, Norway.

Received: 17 December 2019 Accepted: 9 November 2020

Published online: 20 November 2020

\section{References}

1. United Nations Department of Economic and Social Affairs PD. Profiles of Ageing 2019: United Nations; 2019. Available from: https://population.un. org/ProfilesOfAgeing2019/index.html. Cited 11 November 2019.

2. Linnet K, Gudmundsson LS, Birgisdottir FG, Sigurdsson EL, Johannsson M, Tomasdottir MO, et al. Multimorbidity and use of hypnotic and anxiolytic drugs: cross-sectional and follow-up study in primary healthcare in Iceland. BMC Fam Pract. 2016;17(1):69.

3. Tomasdottir MO, Getz L, Sigurdsson JA, Petursson H, Kirkengen AL, Krokstad $\mathrm{S}$, et al. Co-and multimorbidity patterns in an unselected Norwegian population: cross-sectional analysis based on the HUNT study and theoretical reflections concerning basic medical models. Eur J Pers Cent Healthc. 2014;2(3):335-45.

4. Mossialos E, Wenzl M, Osborn R, Sarnak D. 2015 international profiles of health care systems: Canadian Agency for Drugs and Technologies in health; 2016.

5. Ågotnes G, McGregor MJ, Lexchin J, Doupe MB, Müller B, Harrington C. An international mapping of medical care in nursing homes. Health Services Insights. 2019;12:1178632918825083.

6. Health and Care Services Act, 2011 [Norwegian; Helse- og omsorgstjenesteloven] § 3-2. Available from: https://app.uio.no/ub/ujur/ oversatte-lover/data/lov-20110624-030-eng.pdf. Cited 14 October 2019.

7. Wergeland JN, Selbæk G, Bergh S, Soederhamn U, Kirkevold ØJD. Predictors for nursing home admission and death among community-dwelling people 70 years and older who receive domiciliary care. Dement Geriatr Cogn Dis Extra. 2015;5(3):320-9.

8. Gnjidic D, Stanaway FF, Cumming R, Waite L, Blyth F, Naganathan V, et al. Mild cognitive impairment predicts institutionalization among older men: a population-based cohort study (Mild Cognitive Impairment and Institutionalization). PLoS One. 2012;7(9):e46061.

9. Wang SY, Shamliyan TA, Talley KM, Ramakrishnan R, Kane RL. Not just specific diseases: systematic review of the association of geriatric syndromes with hospitalization or nursing home admission. Arch Gerontol Geriatr. 2013;57(1):16-26.

10. Luppa M, Luck T, Weyerer S, König H-H, Brähler E, Riedel-Heller SG. Prediction of institutionalization in the elderly. A systematic review. Age Ageing. 2009;39(1):31-8.

11. Bergh S, Holmen J, Saltvedt I, Tambs K, Selbæk G. Demens og nevropsykiatriske symptomer hos sykehjemspasienter i Nord-Trøndelag. Tidsskr Nor Laegeforen. 2012;132(17):1956-59.

12. Helvik A-S, Engedal K, Benth JŠ, Selbæk G. Prevalence and severity of dementia in nursing home residents. Dement Geriatr Cogn Dis. 2015;40(3-4):166-77.

13. Selbaek G, Kirkevold O, Engedal K. The prevalence of psychiatric symptoms and behavioural disturbances and the use of psychotropic drugs in Norwegian nursing homes. Int J Geriatr Psychiatry. 2007;22(9):843-9.

14. Swedish Council on Health Technology A. SBU Systematic Reviews. Dementia -- Caring, Ethics, Ethnical and Economical Aspects: A Systematic Review. Stockholm: Swedish Council on Health Technology Assessment (SBU); 2008.

15. Goodman RA, Lochner KA, Thambisetty M, Wingo TS, Posner SF, Ling SM. Prevalence of dementia subtypes in United States Medicare fee-for-service beneficiaries, 2011-2013. Alzheimers Dement. 2017;13(1):28-37. 
16. WHO. The ICD-10 classification of mental and behavioural disorders. Diagnostic criteria for research. Genéve: World Health Organization; 1993.

17. Skoldunger A, Wimo A, Sjogren K, Bjork S, Backman A, Sandman PO, et al. Resource use and its association to cognitive impairment, ADL functions, and behavior in residents of Swedish nursing homes: results from the $\mathrm{U}$-age program (SWENIS study). Int J Geriatr Psychiatry. 2018;34(1):130-6.

18. Sourial R, McCusker J, Cole M, Abrahamowicz M. Agitation in demented patients in an acute care hospital: prevalence, disruptiveness, and staff burden. Int Psychogeriatr. 2001;13(2):183-97.

19. Broady TR, Saich F, Hinton T. Caring for a family member or friend with dementia at the end of life: a scoping review and implications for palliative care practice. Palliat Med. 2018;32(3):643-56.

20. Schulz R, Martire LM. Family caregiving of persons with dementia: prevalence, health effects, and support strategies. Am J Geriatr Psychiatry. 2004;12(3):240-9.

21. Bjork S, Juthberg C, Lindkvist M, Wimo A, Sandman PO, Winblad B, et al. Exploring the prevalence and variance of cognitive impairment, pain, neuropsychiatric symptoms and ADL dependency among persons living in nursing homes; a cross-sectional study. BMC Geriatr. 2016;16:154.

22. Selbaek G, Engedal K, Bergh S. The prevalence and course of neuropsychiatric symptoms in nursing home patients with dementia: a systematic review. J Am Med Dir Assoc. 2013;14(3):161-9.

23. Zuidema SU, Derksen E, Verhey FR, Koopmans RT. Prevalence of neuropsychiatric symptoms in a large sample of Dutch nursing home patients with dementia. Int J Geriatr Psychiatry. 2007;22(7):632-8.

24. Selbaek G, Engedal K, Benth JŠ, Bergh S. The course of neuropsychiatric symptoms in nursing-home patients with dementia over a 53-month follow-up period. Int Psychogeriatr. 2014;26(1):81-91.

25. Helvik A-S, Selbæk G, Benth JŠ, Røen I, Bergh S. The course of neuropsychiatric symptoms in nursing home residents from admission to 30-month follow-up. PLoS One. 2018;13(10):e0206147.

26. Carpenter $\mathrm{Gl}$, Hastie $\mathrm{CL}$, Morris JN, Fries BE, Ankri J. Measuring change in activities of daily living in nursing home residents with moderate to severe cognitive impairment. BMC Geriatr. 2006;6:7.

27. Dodge HH, Kadowaki T, Hayakawa T, Yamakawa M, Sekikawa A, Ueshima H. Cognitive impairment as a strong predictor of incident disability in specific ADL-IADL tasks among community-dwelling elders: the Azuchi study. Gerontologist. 2005:45(2):222-30.

28. Helvik AS, Engedal K, Benth JS, Selbaek G. A 52 month follow-up of functional decline in nursing home residents - degree of dementia contributes. BMC Geriatr. 2014;14:45.

29. Maki Y, Sakurai T, Okochi J, Yamaguchi H, Toba K. Rehabilitation to live better with dementia. Geriatr Gerontol Int. 2018;18(11):1529-36.

30. Desai AK, Grossberg GT, Sheth DN. Activities of daily living in patients with dementia: clinical relevance, methods of assessment and effects of treatment. CNS Drugs. 2004;18(13):853-75

31. Helvik A-S, Hagseth LD, Bergh S, Saltyte-Benth J, Kirkevold O, Selbaek G. A 36-month follow-up of decline in activities of daily living in individuals receiving domiciliary care. (Clinical report). BMC Geriatr. 2015;15(1):47.

32. Slachevsky A, Forno G, Barraza P, Mioshi E, Delgado C, Lillo P, et al. Mapping the neuroanatomy of functional decline in Alzheimer's disease from basic to advanced activities of daily living. J Neurol. 2019;266(6):1310-22.

33. Mioshi E, Hodges JR, Hornberger M. Neural correlates of activities of daily living in frontotemporal dementia. J Geriatr Psychiatry Neurol. 2013;26(1): 51-7.

34. Potkin SG. The ABC of Alzheimer's disease: ADL and improving day-to-day functioning of patients. Int Psychogeriatr. 2002;14(Suppl 1):7-26.

35. Williams BC, Fries BE, Foley WJ, Schneider D, Gavazzi M. Activities of daily living and costs in nursing homes. Health Care Financ Rev. 1994;15(4):117-35.

36. McConnell ES, Branch LG, Sloane RJ, Pieper CF. Natural history of change in physical function among long-stay nursing home residents. Nurs Res. 2003; 52(2):119-26.

37. McConnell ES, Pieper CF, Sloane RJ, Branch LG. Effects of cognitive performance on change in physical function in long-stay nursing home residents. J Gerontol A Biol Sci Med Sci. 2002;57(12):M778-84.

38. Banaszak-Holl J, Liang J, Quinones A, Cigolle C, Lee I-C, Verbrugge LM. Trajectories of functional change among long stayers in nursing homes: does baseline impairment matter? J Aging Health. 2011;23(5):862-82.

39. Millán-Calenti JC, Tubío J, Pita-Fernández S, Rochette S, Lorenzo T, Maseda A. Cognitive impairment as predictor of functional dependence in an elderly sample. Arch Gerontol Geriatr. 2012;54(1):197-201.
40. Stuck AE, Walthert JM, Nikolaus T, Büla CJ, Hohmann C, Beck JC. Risk factors for functional status decline in community-living elderly people: a systematic literature review. Soc Sci Med. 1999;48(4):445-69.

41. Mlinac ME, Feng MC. Assessment of activities of daily living, self-care, and Independence. Arch Clin Neuropsychol. 2016;31(6):506-16.

42. Ćwirlej-Sozańska AB, Sozański B, Wiśniowska-Szurlej A, WilmowskaPietruszyńska A. An assessment of factors related to disability in ADL and IADL in elderly inhabitants of rural areas of South-Eastern Poland. Ann Agric Environ Med. 2018;25(3):504-11.

43. Røen IM, Selbæk G, Kirkevold Ø, Engedal K, Testad I, Bergh S. Resource use and disease course in dementia-nursing home (REDIC-NH), a longitudinal cohort study; design and patient characteristics at admission to Norwegian nursing homes. BMC Health Serv Res. 2017;17(1):365.

44. Lawton MP, Brody EM. Assessment of older people: self-maintaining and instrumental activities of daily living. Gerontologist. 1969:9(3):179-86.

45. Hughes $C P$, Berg L, Danziger WL, Coben LA, Martin RL. A new clinical scale for the staging of dementia. Br J Psychiatry. 1982;140:566-72.

46. Morris JC. The clinical dementia rating (CDR): current version and scoring rules. Neurology. 1993:43(11):2412-4.

47. O'Bryant SE, Waring SC, Cullum CM, Hall J, Lacritz L, Massman PJ, et al. Staging dementia using clinical dementia rating scale sum of boxes scores: a Texas Alzheimer's research consortium study. Arch Neurol. 2008;65(8): $1091-5$.

48. Mjorud M, Kirkevold M, Rosvik J, Selbaek G, Engedal K. Variables associated to quality of life among nursing home patients with dementia. Aging Ment Health. 2014;18(8):1013-21.

49. Cummings $\mathrm{J}$. The neuropsychiatric inventory: assessing psychopathology in dementia patients. Neurology. 1997;48(5 Suppl 6):S10-6.

50. Selbaek G, Kirkevold O, Sommer OH, Engedal K. The reliability and validity of the Norwegian version of the neuropsychiatric inventory, nursing home version (NPI-NH). Int Psychogeriatr. 2008;20(2):375-82.

51. Selbæk G, Engedal K. Stability of the factor structure of the neuropsychiatric inventory in a 31-month follow-up study of a large sample of nursing-home patients with dementia. Int Psychogeriatr. 2012;24(1):62-73.

52. Colombo M, Vitali S, Cairati M, Vaccaro R, Andreoni G, Guaita A. Behavioral and psychotic symptoms of dementia (BPSD) improvements in a special care unit: a factor analysis. Arch Gerontol Geriatr. 2007;44(1):113-20.

53. Lyketsos CG, Galik E, Steele C, Steinberg M, Rosenblatt A, Warren A, et al. The general medical health rating: a bedside global rating of medical comorbidity in patients with dementia. J Am Geriatr Soc. 1999:47(4):487-91.

54. Leoutsakos JM, Han D, Mielke MM, Forrester SN, Tschanz JT, Corcoran CD, et al. Effects of general medical health on Alzheimer's progression: the Cache County dementia progression study. Int Psychogeriatr. 2012;24(10): 1561-70.

55. Lyketsos CG, Toone L, Tschanz J, Rabins PV, Steinberg M, Onyike CU, et al. Population-based study of medical comorbidity in early dementia and "cognitive impairment, no dementia (CIND)": association with functional and cognitive impairment: the Cache County study. Am J Geriatr Psychiatry. 2005;13(8):656-64.

56. Sylliaas $H$, Selbaek $G$, Bergland A. Do behavioral disturbances predict falls among nursing home residents? Aging Clin Exp Res. 2012;24(3):251-6.

57. WHO. ATC/DDD index 2011: World health organization collaborating Centre for Drugs Statistics Methodology; 2013 Available from: https://www.whocc. no/atc_ddd_index/. Cited 7 May 2019.

58. The Health Research Act, 2008 [Norwegian: Helseforskningsloven] § 4-17. Available from: https://app.uio.no/ub/ujur/oversatte-lover/data/lov-2008062 0-044-eng.pdf. Cited 29 October 2020.

59. Hishikawa N, Fukui Y, Sato K, Kono S, Yamashita T, Ohta Y, et al. Characteristic features of cognitive, affective and daily living functions of late-elderly dementia. Geriatr Gerontol Int. 2016;16(4):458-65.

60. Kaup BA, Loreck D, Gruber-Baldini AL, German P, Menon AS, Zimmerman S, et al. Depression and its relationship to function and medical status, by dementia status, in nursing home admissions. Am J Geriatr Psychiatry. 2007; 15(5):438-42.

61. Burge E, von Gunten A, Berchtold A. Factors favoring a degradation or an improvement in activities of daily living (ADL) performance among nursing home $(\mathrm{NH})$ residents: a survival analysis. Arch Gerontol Geriatr. 2013;56(1): $250-7$.

62. Haibo X, Shifu X, Pin NT, Chao C, Guorong M, Xuejue L, et al. Prevalence and severity of behavioral and psychological symptoms of dementia (BPSD) 
in community dwelling Chinese: findings from the Shanghai three districts study. Aging Ment Health. 2013;17(6):748-52.

63. Peng GP, Feng Z, He FP, Chen ZQ, Liu XY, Liu P, et al. Correlation of hippocampal volume and cognitive performances in patients with either mild cognitive impairment or Alzheimer's disease. CNS Neurosci Ther. 2015; 21(1):15-22.

64. Rosenberg PB, Nowrangi MA, Lyketsos CG. Neuropsychiatric symptoms in Alzheimer's disease: What might be associated brain circuits? Mol Aspects Med. 2015;43-44:25-37.

65. Gauthier S, Lopez OL, Waldemar G, Jones RW, Cummings J, Zhang R, et al. Effects of donepezil on activities of daily living: integrated analysis of patient data from studies in mild, moderate and severe Alzheimer's disease. Int Psychogeriatr. 2010;22(6):973-83.

66. Kishi T, Matsunaga S, Oya K, Ikuta T, Iwata N. Protection against Brain Atrophy by Anti-dementia Medication in Mild Cognitive Impairment and Alzheimer's Disease: Meta-Analysis of Longitudinal Randomized PlaceboControlled Trials. Int J Neuropsychopharmacol. 2015;18(12):1-7.

67. Miller $L S$, Brown $C L$, Mitchell MB, Williamson GM. Activities of daily living are associated with older adult cognitive status: caregiver versus self-reports. J Appl Gerontol. 2013;32(1):3-30

68. Snowdon DA, Ostwald SK, Kane RL. Education, survival, and independence in elderly Catholic sisters, 1936-1988. Am J Epidemiol. 1989:130(5):999-1012.

69. Burman J, Sembiah S, Dasgupta A, Paul B, Pawar N, Roy A. Assessment of poor functional status and its predictors among the elderly in a rural area of West Bengal. J Midlife Health. 2019;10(3):123-30.

70. Xu R, Zhou X, Cao S, Huang B, Wu C, Zhou X, et al. Health Status of the Elderly and Its Influence on Their Activities of Daily Living in Shangrao, Jiangxi Province. Int J Environ Res Public Health. 2019;16(10):1771.

\section{Publisher's Note}

Springer Nature remains neutral with regard to jurisdictional claims in published maps and institutional affiliations.

Ready to submit your research? Choose BMC and benefit from:

- fast, convenient online submission

- thorough peer review by experienced researchers in your field

- rapid publication on acceptance

- support for research data, including large and complex data types

- gold Open Access which fosters wider collaboration and increased citations

- maximum visibility for your research: over $100 \mathrm{M}$ website views per year

At $\mathrm{BMC}$, research is always in progress.

Learn more biomedcentral.com/submissions 